Supplement of

Atmospheric new particle formation characteristics in the Arctic as measured at Mount Zeppelin, Svalbard, from 2016 to 2018

Haebum Lee et al.

5

Correspondence to: Kihong Park (kpark@gist.ac.kr) and Young-Jun Yoon (yjyoon@kopri.re.kr) 


\section{Chlorophyll-a $\left(\mathrm{mg} \mathrm{m}^{-3}\right)$}
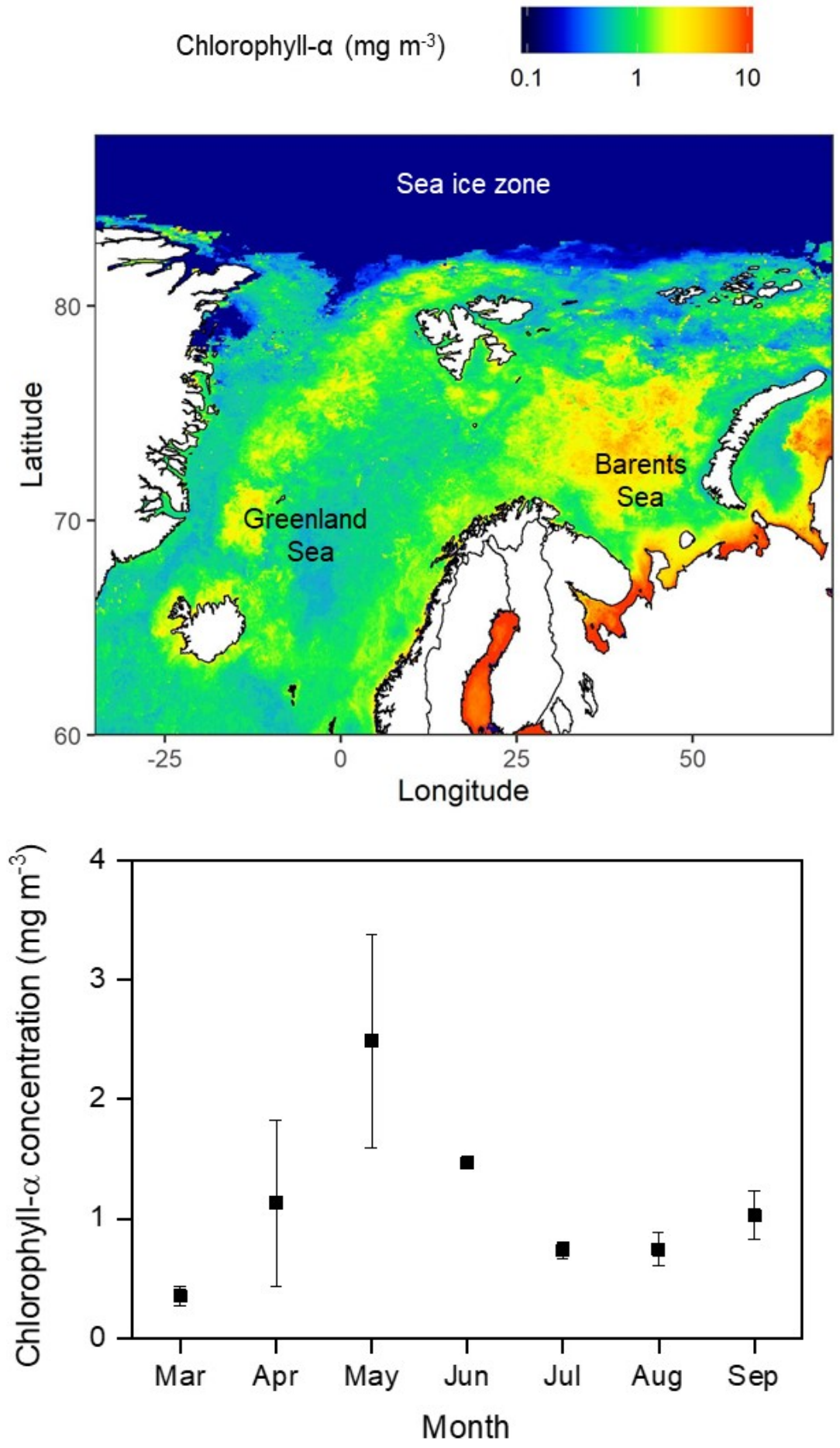

Figure S1. MODIS monthly mean satellite-derived chlorophyll- $\alpha$ concentration map at $4 \mathrm{~km}$ resolution (top) and values (bottom) around Svalbard from March to September, 2016 to 2018. Error bars indicate one standard deviation from the mean. 
Table S1. Average concentrations of ionic species $\left(\mathrm{Na}^{+}, \mathrm{Mg}^{2+}, \mathrm{K}^{+}, \mathrm{NH}_{4}{ }^{+}, \mathrm{NO}_{3}{ }^{-}, \mathrm{SO}_{4}{ }^{2-}\right.$, and $\left.\mathrm{Cl}^{-}\right)$in particulate matter in different seasons from 2016 to 2018.

\begin{tabular}{ccccc}
\hline $\begin{array}{c}\text { Mass concentration } \\
\left(\mu \mathrm{g} \mathrm{m}^{-3}\right)\end{array}$ & Spring & Summer & Fall & Winter \\
\hline $\mathrm{Na}^{+}$ & $0.19 \pm 0.15$ & $0.13 \pm 0.15$ & $0.18 \pm 0.17$ & $0.25 \pm 0.18$ \\
$\mathrm{Mg}^{2+}$ & $0.03 \pm 0.02$ & $0.02 \pm 0.02$ & $0.03 \pm 0.02$ & $0.04 \pm 0.03$ \\
$\mathrm{~K}^{+}$ & $0.03 \pm 0.02$ & $0.03 \pm 0.02$ & $0.02 \pm 0.02$ & $0.02 \pm 0.02$ \\
$\mathrm{NH}^{+}$ & $0.04 \pm 0.03$ & $0.03 \pm 0.02$ & $0.02 \pm 0.01$ & $0.02 \pm 0.02$ \\
\hline $\mathrm{NO}_{3}^{-}$ & $0.08 \pm 0.05$ & $0.06 \pm 0.04$ & $0.06 \pm 0.04$ & $0.07 \pm 0.04$ \\
$\mathrm{SO}_{4}{ }^{-}$ & $0.43 \pm 0.27$ & $0.21 \pm 0.17$ & $0.22 \pm 0.21$ & $0.28 \pm 0.21$ \\
$\mathrm{Cl}^{-}$ & $0.26 \pm 0.25$ & $0.18 \pm 0.24$ & $0.28 \pm 0.28$ & $0.38 \pm 0.28$ \\
\hline
\end{tabular}

15 